\title{
Intramolecular hydrogen bonding of (+)-biotin and biotin derivatives in organic solvents
}

\author{
Geoffrey T. Crisp* and Yu-Lin Jiang \\ Department of Chemistry, Adelaide University, Adelaide, South Australia, 5005 Australia \\ E-mail: geoffrey.crisp@adelaide.edu.au \\ (received 10 Mar 01; accepted 08 Aug 01; published on the web 16 Aug 01)
}

\begin{abstract}
The intramolecular hydrogen bonding of (+)-biotin and biotin derivatives in mixtures of $\mathrm{CDCl}_{3}$ and DMSO- $\mathrm{d}_{6}$ was investigated by ${ }^{1} \mathrm{H}$ NMR spectroscopy. The dynamic changes observed in the chemic al shifts for the 1-NH and 3-NH protons with changes in solvent composition and temperature confirmed the presence of an intramolecular hydrogen bond between the valeryl side chain hydrogen bond acceptor and the 3-NH proton in a range of biotin derivatives.
\end{abstract}

Keywords: Biotin, intramolecular, hydrogen bonding, NMR

\section{Introduction}

(+)-Biotin, 1, is involved as an enzyme cofactor in a variety of carboxylase, decarboxylase and transcarboxylase reactions. ${ }^{1,2}$ The specificity inherent in the reversible carboxylation of biotin involving the electrophilic substitution of the 1-NH proton by the carboxylate group has long been known. ${ }^{3,4}$ Previous reports have demonstrated the more rapid rate of exchange for the 1-NH proton compared to the 3-NH proton in both biotin itself and biotin methyl ester by measurements involving the rate of $\mathrm{D}_{2} \mathrm{O}$ exchange in DMSO- $\mathrm{d}_{6}$ and NMR saturation transfer experiments. $^{4,5,6,7}$ This increased rate of exchange was attributed to an intramolecular hydrogen bond formed between the carboxylate group in the valeryl side chain and the 3-NH proton and NOESY measurements confirmed the presence of a conformation similar to that shown in Figure 1. ${ }^{5} \mathrm{~A}$ number of ${ }^{1} \mathrm{H}$ and ${ }^{13} \mathrm{C}$ NMR studies on biotin has been reported and a complete assignment for the observed resonances is available. ${ }^{5,8,9}$

Previous NMR studies on biotin have been conducted at concentrations $=17 \mathrm{mM}^{5}$ and so both inter-and intramolecular hydrogen bonding might be expected in solution, depending on the 
solvent. ${ }^{10}$ In addition, we were not aware of any published data for simple biotin derivatives at low concentration that demonstrated temperature dependent NMR chemical shifts supporting the proposed intramolecular hydrogen bonding between 3-NH and the carboxyl carbonyl on the valeryl side chain. In this paper we report on the effect of solvent composition in the mixed solvent $\mathrm{CDCl}_{3} / \mathrm{DMSO}-\mathrm{d}_{6}$ on the chemical shifts of the $1-\mathrm{NH}$ and $3-\mathrm{NH}$ protons and on the temperature dependence of the 1-NH and 3-NH protons in biotin and its derivatives in dilute solutions.

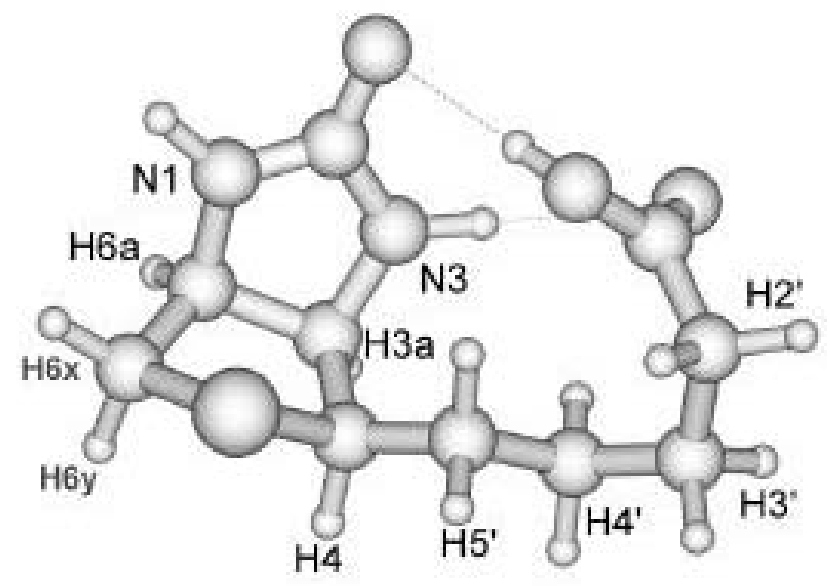

Figure 1. Folded conformation of biotin with intramolecular hydrogen bonding.

\section{Results and Discussion}

\section{Preparation of biotin derivatives}

In order to investigate the intramolecular hydrogen bonding of biotin a series of derivatives, 2-8, was prepared using literature procedures.<smiles>[X]CCCC[C@H]1SC[C@@H]2NC(=O)N[C@@H]21</smiles>

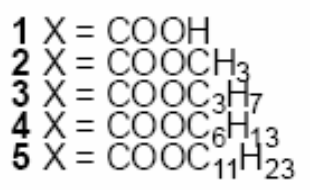

$6 \mathrm{X}=\mathrm{COO}\left(4-\mathrm{NO}_{2} \mathrm{Ph}\right)$

$7 \mathrm{X}=\mathrm{CH}_{2} \mathrm{OH}$

$8 \mathrm{X}=\mathrm{CH}_{2} \mathrm{OSO}_{2} \mathrm{CH}_{3}$

$9 \mathrm{X}=\mathrm{CH}_{2} \mathrm{I}$
Nal/acetone 


\section{Nmr spectra of (+)-biotin}

(+)-Biotin, 1, does not dissolve significantly in $\mathrm{CDCl}_{3}$ and so $\mathrm{DMSO}-\mathrm{d}_{6}$ was used for the preparation of homogeneous and stable solutions. The assignments for the ${ }^{1} \mathrm{H}$ NMR spectrum for biotin were H4' (1.465, m, 2H); H5'b+H3'a (1.642, m, 3H); H5'a (1.737, m, 1H); H3'b (2.292, t, $\mathrm{J}=7.2 \mathrm{~Hz}, 2 \mathrm{H})$; H6x (2.756, d, J=13.2Hz, 1H); H6y (2.888, dd, J=13.2Hz, 4.8Hz, 1H); H4 (3.148, m, 1H); HЗа (4.275, m, 1H); H6a (4.466, m, 1H); 3NH (5.586, s, 1H); 1-NH (5.681, s, 1H), with H2' under the solvent resonance (Figure 2).

Previous ${ }^{1} \mathrm{H}$ NMR data for biotin in DMSO- $\mathrm{d}_{6}$ showed that the 3-NH proton occurred further downfield compared to the 1-NH proton. ${ }^{5,8,9}$ The 2D-COSY spectrum for a $5 \mathrm{mM}$ solution of biotin in $10 \% \mathrm{DMSO}_{-} \mathrm{d}_{6}$ and $90 \% \mathrm{CDCl}_{3}$ at $\mathrm{rt}$, however, indicated that the $1 \mathrm{NH}$ proton was further downfield, rather than the expected 3-NH (Figure 3). The 2DROESY NMR spectrum of biotin under these condition displayed cross peaks between H3a and methylene protons H4', between H4 and H4' and between 3-NH and H4' (Figure 4).

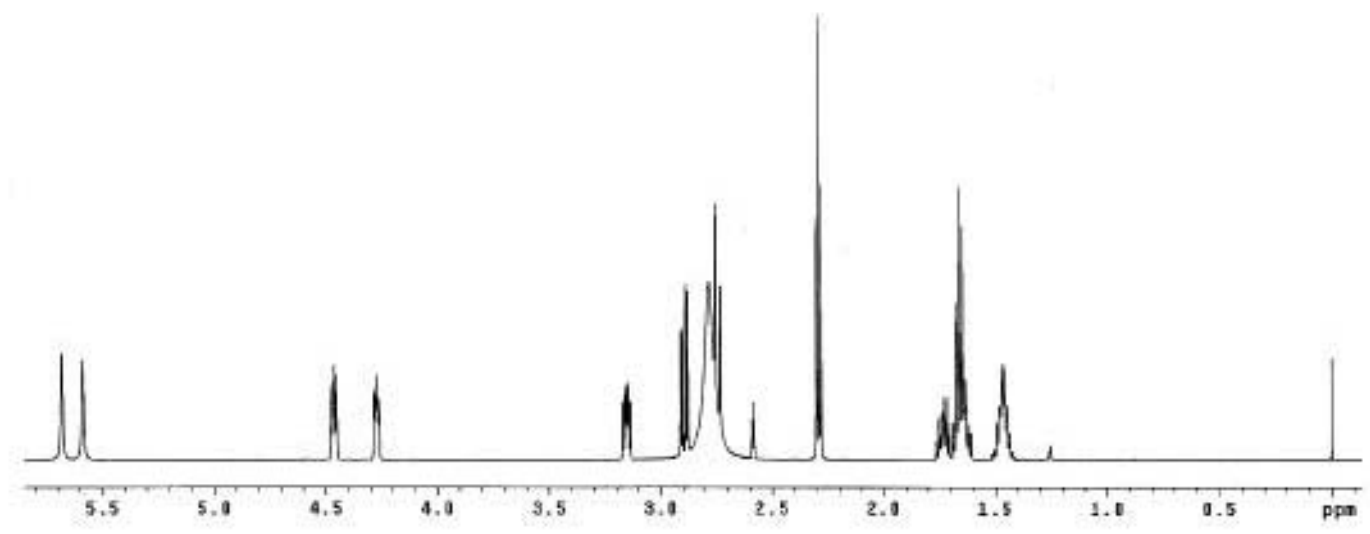

Figure 2. ${ }^{1} \mathrm{H}$ NMR spectrum of (+)-biotin in $10 \% \mathrm{DMSO}^{-\mathrm{d}_{6}}$ and $90 \% \mathrm{CDCl}_{3}$. 


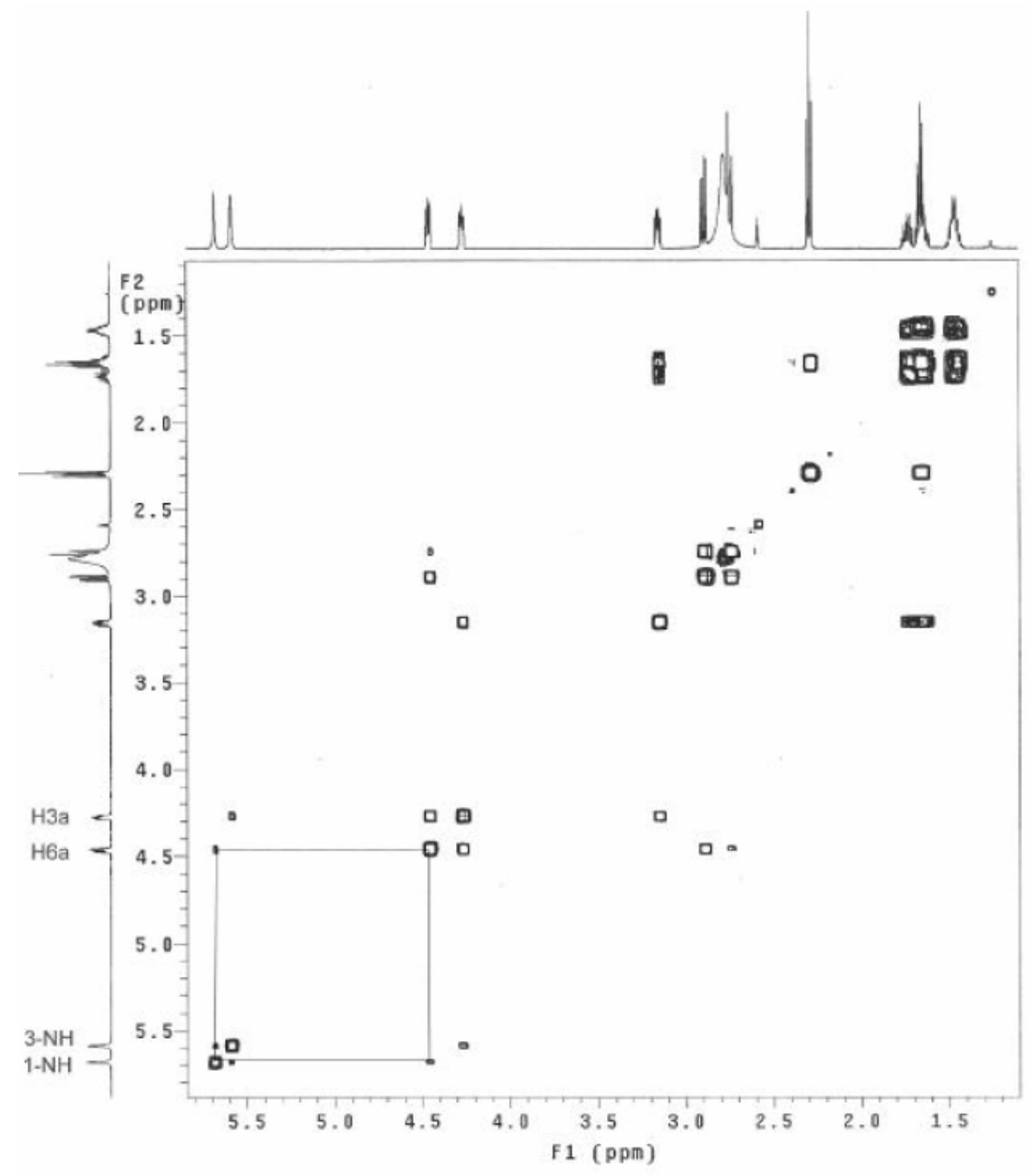

Figure 3. COSY NMR spectrum of biotin $5 \mathrm{mM} 10 \% \mathrm{DMSO}-\mathrm{d}_{6}$ and $90 \% \mathrm{CDCl}_{3}$. 


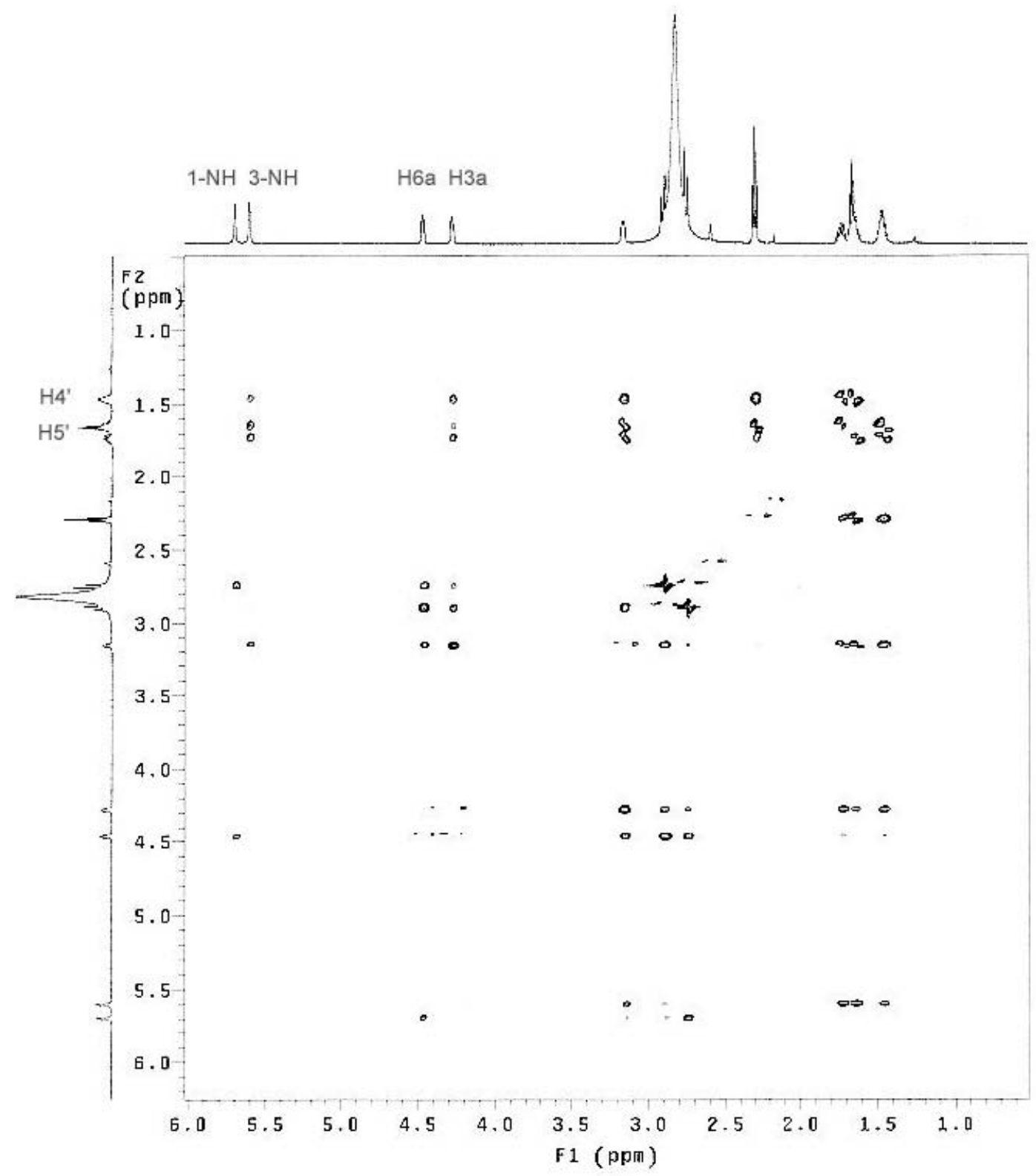

Figure 4. ROESY NMR spectrum of biotin 5mM 10\%DMSO-d $\mathrm{d}_{6}$ and $90 \% \mathrm{CDCl}_{3}$.

Given the apparent reversal in the assignments for the 3-NH and 1-NH protons in $10 \%$ DMSO- $\mathrm{d}_{6}$ and $90 \% \mathrm{CDCl}_{3}$, we investigated the effect of solvent composition on biotin ${ }^{1} \mathrm{H} \mathrm{NMR}$ signals and the results for 3-NH and 1-NH are summarized in Figure 5. It is apparent that the addition of increasing proportions of DMSO- $\mathrm{d}_{6}$ to $\mathrm{CDCl}_{3}$ causes a dramatic downfield shift in the ureido protons. When the proportion of DMSO- $\mathrm{d}_{6}$ in the mixed solvent was $4.0 \%$, the $3-\mathrm{NH}$ proton was downfield from 1- $\mathrm{NH}$, suggesting that $3 \mathrm{NH}$ was involved in intramolecular hydrogen bonding. As the proportion of DMSO- $\mathrm{d}_{6}$ was increased the resonance for 3-NH moved upfield, 
whereas the resonance for 1-NH moved downfied, consistent with a reduction in intramolecular hydrogen bonding for 3NH. At 6.0\% DMSO- $\mathrm{d}_{6}$ content the chemical shifts of both 1-NH and 3$\mathrm{NH}$ became coincident and as the proportion of DMSO- $\mathrm{d}_{6}$ was increased further, both 1-NH and 3NH moved downfield. Figure 5 shows that the resonance for 1-NH moved further downfield than that of 3-NH for DMSO- $\mathrm{d}_{6}$ content between $6.6 \%$ and $20.0 \%$. When the content of DMSO$\mathrm{d}_{6}$ was $26.7 \%$, the chemical shifts for $1-\mathrm{NH}$ and 3-NH again became coincident, and increasing the content of DMSO- $\mathrm{d}_{6}$ above 33.3\% caused 3-NH to be further downfield than 1-NH. Previous NMR assignments for biotin have usually assumed that 3-NH resonated further downfield compared to 1-NH and the present results have highlighted the need to determine the effect of solvent composition on the chemical shift carefully for protons capable of hydrogen bonding.

At room temperature, no intermolecular amide-amide hydrogen bonding was detected in a $1 \mathrm{mM}$ solution of peptide in halogenated solvents, such as $\mathrm{CD}_{2} \mathrm{Cl}_{2}$ and $\mathrm{CDCl}_{3}{ }^{10}$ When polar organic solvents were used, such as $\mathrm{CH}_{3} \mathrm{CN}$, the concentration of peptide could be raised to $10 \mathrm{mM}$ before significant intermolecular hydrogen bonding was detected. ${ }^{10}$ Therefore, the solution of biotin at $5 \mathrm{mM}$ in a mixed solvent of $\mathrm{CDCl}_{3}$ and $\mathrm{DMSO}-\mathrm{d}_{6}$ would be expected to be substantially free of intermolecular hydrogen bonding. 


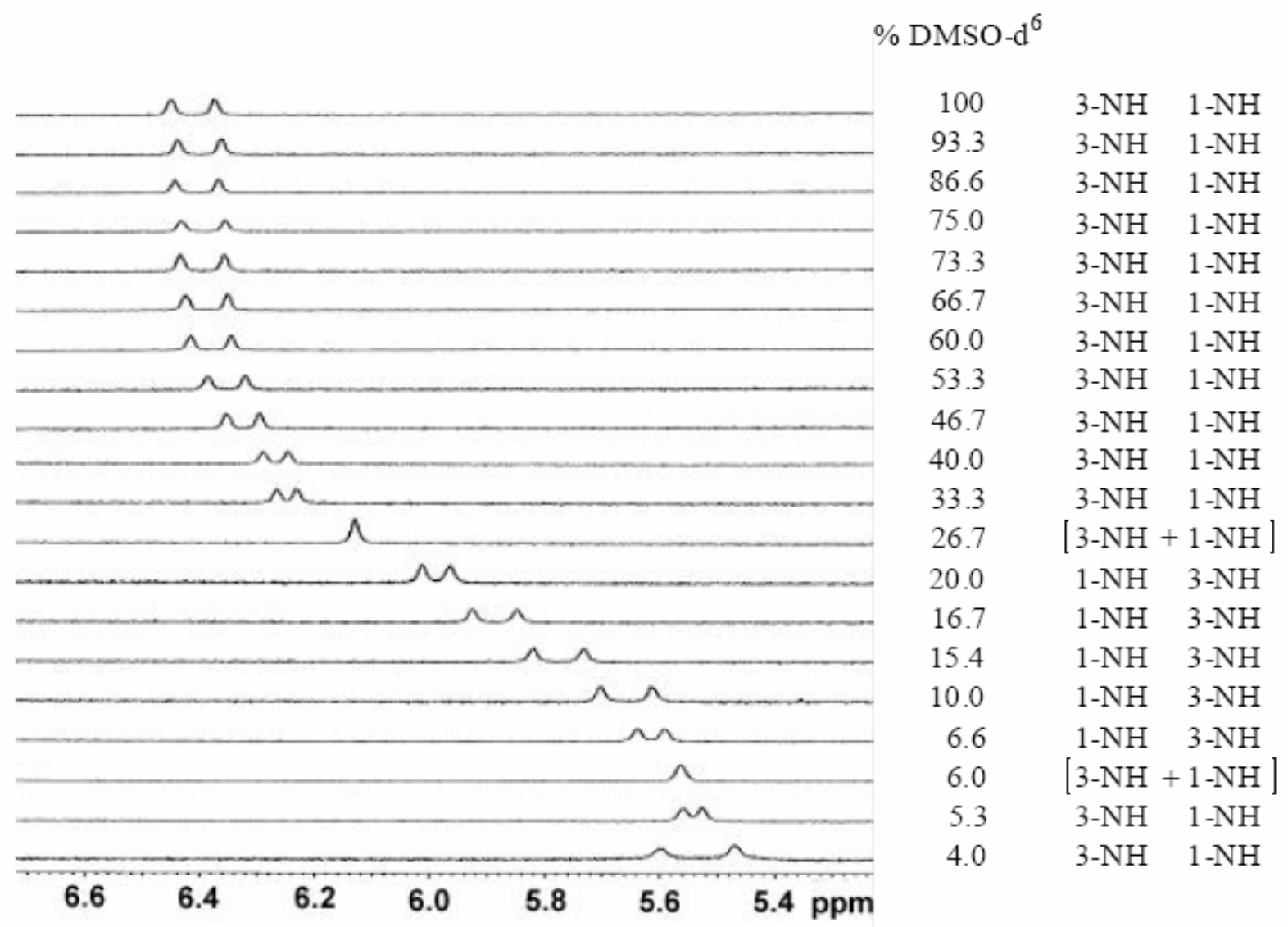

Figure 5. ${ }^{1} \mathrm{H}$ NMR of 3-NH and 1-NH of biotin in mixtures of DMSO-d $\mathrm{d}_{6}$ and $\mathrm{CDCl}_{3}$.

\section{Variable temperature ${ }^{1} \mathbf{H}$ NMR of biotin derivatives}

The temperature dependence of amide protons, the $\Delta \delta \mathrm{NH} / \Delta \mathrm{T}$ value, provides an indication of the efficacy of intramolecular hydrogen bonding. Non-hydrogen bonded amide protons generally show a small temperature dependence, $<3 \mathrm{ppb} / \mathrm{K} .{ }^{10,11}$ In order to confirm the degree of intramolecular hydrogen bonding of biotin and its derivatives (1-9), the temperature dependence was determined at $1 \mathrm{mM}$ in $\mathrm{CDCl}_{3}$ and shown in Table 1 (2 \% DMSO- $\mathrm{d}_{6}$ and $98 \% \mathrm{CDCl}_{3}$ for biotin).

The $\Delta \delta \mathrm{NH} / \Delta \mathrm{T}$ value for both $1-\mathrm{NH}$ and $3-\mathrm{NH}$ of compound 9 was $3.8 \mathrm{ppb} / \mathrm{K}$, indicating insignificant intramolecular hydrogen bonding and confirming that 9 would be a suitable standard for comparing the remaining biotin derivatives. As the data in Table 1 shows, for compounds 2-8, the $\Delta \delta \mathrm{NH} / \Delta \mathrm{T}$ values for 3-NH were much higher than $3 \mathrm{ppb} / \mathrm{K}$, indicating that in each case 3-NH was involved in intramolecular hydrogen bonding. 
Table 1. Temperature dependence, $\Delta \delta \mathrm{NH} / \Delta \mathrm{T}$ in $\mathrm{ppb} / \mathrm{K}$, of 1-9 at $1 \mathrm{mM}$ in $\mathrm{CDCl}_{3}$

\begin{tabular}{cccccccccc}
\hline Compound & $\mathbf{1}^{\text {a }}$ & $\mathbf{2}$ & $\mathbf{3}$ & $\mathbf{4}$ & $\mathbf{5}$ & $\mathbf{6}$ & $\mathbf{7}$ & $\mathbf{8}$ & $\mathbf{9}$ \\
\hline 1-NH & 7.9 & 5.7 & 6.2 & 7.0 & 6.6 & 4.6 & 7.6 & 5.8 & 3.8 \\
& & & & & & & & & \\
$3-\mathrm{NH}$ & 11.7 & 9.1 & 10.2 & 9.9 & 10.2 & 9.2 & 21.1 & 11.4 & 3.8 \\
\hline
\end{tabular}

${ }^{\mathrm{a}} 2 \% \mathrm{DMSO}-\mathrm{d}_{6}$ and $98 \% \mathrm{CDCl}_{3}$

The $\Delta \delta \mathrm{NH} / \Delta \mathrm{T}$ values for $1-\mathrm{NH}$ were higher than expected for 1-8, as previous studies had indicated that favourable conformations involving intramolecular hydrogen bonding between 3$\mathrm{NH}$ and the valeryl carbonyl were possible but no suggestion of intramolecular hydrogen bonding involving 1-NH. ${ }^{5}$ The observed chemical shifts are averaged over the numerous conformations, including those involving extended chains and intramolecular hydrogen bonding. These data do indicate that weak intramolecular bonding is possible between acceptors in the valeryl side chain and the donor on 1-NH.

The geometry of biotin ester $\mathbf{6}$ in $\mathrm{CDCl}_{3}$ at $20 \mathrm{mM}$ was probed with a homonuclear NOESY experiment. Irradiation of H3a revealed the following NOE enhancements, H3' (0.46\%) and H4' (0.48\%); irradiation of H4 revealed the following NOE enhancements H3' (1.94\%), H4' (2.10\%) and H5' (1.31\%); suggesting a conformation analogous to that shown for biotin in Figure 1. The 2D-ROESY spectrum of biotin ester 6 in $\mathrm{CDCl}_{3}$ at room temperature is shown in Figure 6 with cross peaks observed between 3-NH and H3', H4' and H5'. 


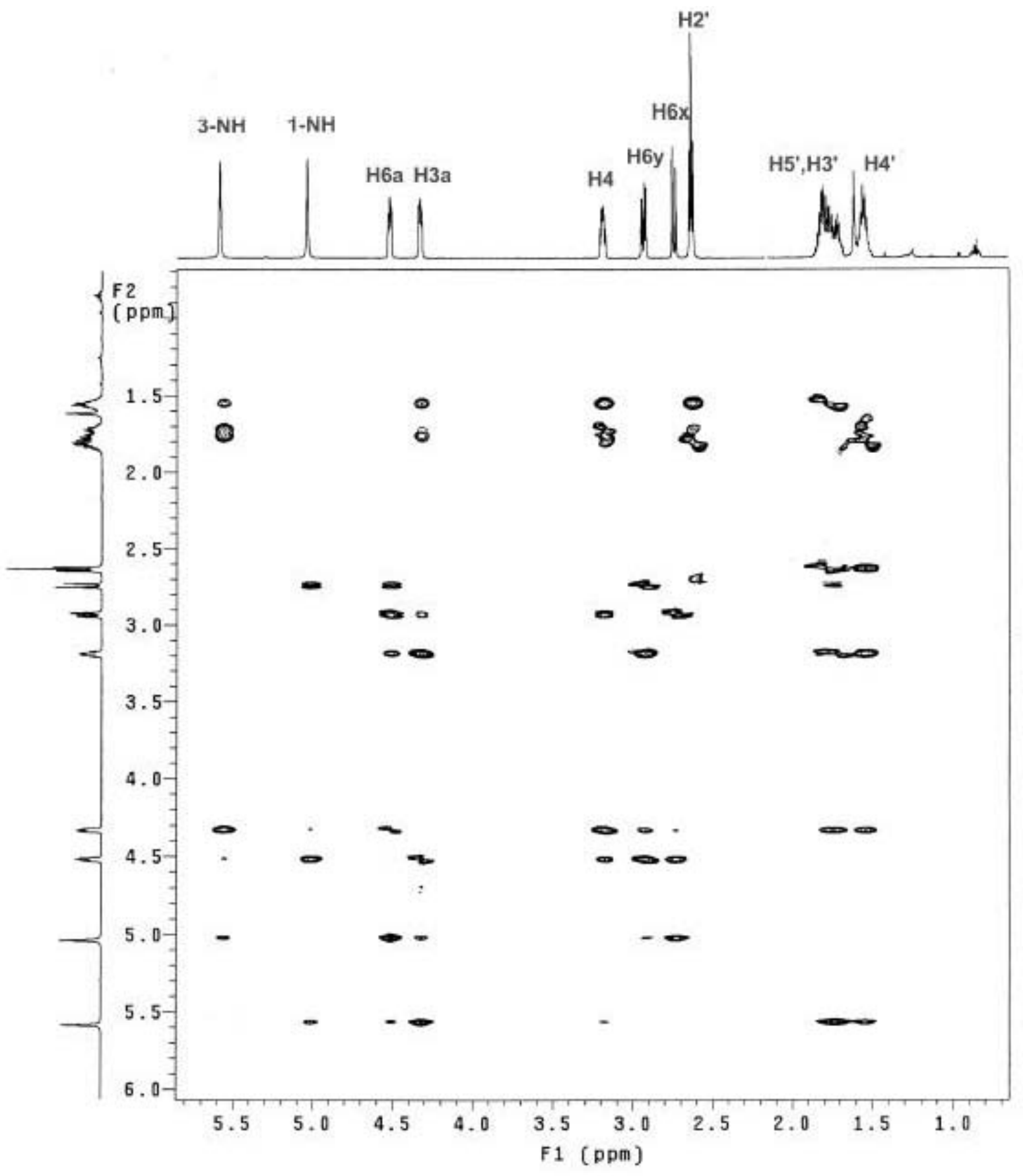

Figure 6. ROESY ${ }^{1} \mathrm{H}$ NMR spectrum of 6 in $\mathrm{CDCl}_{3}$ at room temperature. 
In conclusion, we have shown that there is a need to be cautious in the assignment of ${ }^{1} \mathrm{H}$ NMR spectra for compounds in different solvents when intramolecular hydrogen bonding is possible and confirmed that intramolecular hydrogen bonding between $3 \mathrm{NH}$ and the valeryl side chain is possible in a range of biotin derivatives. In addition, the 1-NH of biotin and its derivatives is also capable of intramolecular hydrogen bonding but to a lesser extent than the previously reported 3-NH.

\section{Experimental Section}

General Procedures. Melting points were recorded on a Reichert hot stage apparatus. ${ }^{1} \mathrm{H}$ and ${ }^{13} \mathrm{C}$ NMR spectra were recorded on a Varian 600 spectrometer in $\mathrm{CDCl}_{3}$ and $\mathrm{DMSO}-\mathrm{d}_{6}$ as solvent with TMS as an internal standard. Chemical shifts were reproducible within $\pm 0.002 \mathrm{ppm}$. $\mathrm{CDCl}_{3}$ was dried over $4 \AA$ molecular sieves for at least one month before use. 2D-COSY, ROESY and NOESY NMR were recorded on a Varian 600 NMR spectrometer. Variable temperature NMR experiments were performed under the automatic control of the attachments on the Bruker ACP-300 and Varian 600 spectrometers and the temperature was maintained within a $\pm 0.02^{\circ} \mathrm{C}$.

Compounds $\mathbf{2}^{12}, \mathbf{3}^{13}, \mathbf{4}^{13}, \mathbf{5}^{13}, \mathbf{6}^{14}, \mathbf{7}^{15}$ and $\mathbf{8}^{15}$ were prepared by literature procedures.

\section{[3a $S$-(3a , 4b , 6a )]-Tetrahydro-4-(5-iodopentyl)-1H-thieno[3,4-d ]imidazol-2(3H)-one (9)} [3aS-(3a, 4b, 6a)]-Tetrahydro-4-(5-(methylsulfonyl)pentyl)-1H-thieno[3,4-d]imidazol-2(3H)-one (8) $(0.010 \mathrm{~g}, 0.032 \mathrm{mmol})$ was dissolved in acetone $(2 \mathrm{~mL})$ and anhydrous sodium iodide $(0.096 \mathrm{~g}$, $0.64 \mathrm{mmol}$ ) was added. The mixture was stirred overnight at room temperature. The solvent was removed with a stream of nitrogen and the residue was submitted to flash column separation with $8 \% \mathrm{MeOH}$ in $\mathrm{CH}_{2} \mathrm{Cl}_{2}$ as an eluant to give 9 as a light yellow solid in $74 \%(0.008 \mathrm{~g})$. Mp 173$176{ }^{\circ} \mathrm{C} .{ }^{1} \mathrm{H} \mathrm{NMR}\left(\mathrm{CDCl}_{3}, 1 \mathrm{mM}, \mathrm{rt}\right): \delta(\mathrm{ppm})$ 1.460-1.859(m, 8H, $\left.\mathrm{CH}_{2}\right) ; 2.768(\mathrm{~d}, 1 \mathrm{H}, \mathrm{J}=12.6 \mathrm{~Hz}$, H6x); 2.984(dd, 1H, J=12.6Hz, 5.4Hz, H6y); 3.149(m, 1H, H4), 3.172(t, 2H, J=13.8Hz, $\mathrm{CH}_{2}$ ), 4.340(m, 1H, H3a); 4.535(m, 1H, H6a); 4.442(s, 2H, 1-NH, 3-NH). Calc. for $[\mathrm{M}+\mathrm{H}]^{+}$ $\mathrm{C}_{10} \mathrm{H}_{18} \mathrm{NOSI}: 2341.0203$. Found: 341.0192.

\section{Acknowledgements}

We would like to thank the Australian Research Council for the award of an Overseas Postgraduate Research Scholarship to Y-L. Jiang and Dr. S. M. Pyke for valuable discussions on 
nmr spectral data.

This paper is dedicated to Professor D. W. Cameron on the occasion of his retirement in recognition of his outstanding contributions to organic chemistry and teaching.

\section{References}

1. Wood, H. G.; Kumar, G. K. Ann. N. Y. Acad. Sci. 1985, 447, 1.

2. Musashi, Y.; Hamada, T.; Sakaki, S. J. Am. Chem. Soc. 1995, 115, 11320.

3. Knowles, J. R. Annu. Rev. Biochem. 1989, 58, 195.

4. Fry, D. C.; Fox, T. L.; Lane, M. D.; Mildvan, A. S. J. Am. Chem. Soc. 1985, 107, 7659.

5. Tonan, K.; Adachi, K.; Ikawa, S. Spectrochimica Acta Part A 1998, 54, 989.

6. Grasel, J. A. Biochem. 1966, 5, 1851.

7. Perrin, C. L.; Dwyer, T. J. J. Am. Chem. Soc. 1987, 109, 5163.

8. Ikura, M.; Hikichi, K. Org. Magn. Reson. 1982, 20, 266.

9. Bates, H. A.; Rosenblum, S. B. Tetrahedron 1985, 41, 2331.

10. Gellman, S. H.; Dado, G. P.; Liang, G.-B.; Adams, B. R. J. Am. Chem. Soc. 1991, 113, 1164.

11. Tsang, K. Y.; Diaz, H.; Graciani, N.; Kelly, J. W. J. Am. Chem. Soc. 1994, 116, 3988.

12. Liu, F-T; Leonard, N. J. J. Am. Chem. Soc. 1979, 101, 996.

13. Crisp, G. T.; Gore, J. Synth. Commun. 1997, 27, 2203.

14. Bodanszky, M.; Fagan, D. T. J. Am. Chem. Soc. 1977, 99, 235.

15. Islam, I.; Ng, K.; Chong, K. T.; McQuade, T. J.;Hui, J. O.; Wilkinson, K. F.; Rush, B. D.; Ruwart, M. J.; Borchardt, R. T.; Fisher, J. F. J. Med. Chem. 1994, 37, 293. 